\author{
Silvana Naredi \\ Gavin Lambert \\ Peter Friberg \\ Stefan Zäll \\ Elisabeth Edén \\ Bertil Rydenhag \\ Maria Tylman \\ Anders Bengtsson
}

\section{Sympathetic activation and inflammatory response in patients with subarachnoid haemorrhage}

Received: 15 February 2006

Accepted: 14 September 2006

Published online: 13 October 2006

(C) Springer-Verlag 2006

\section{S. Naredi (『)}

Umeå University Hospital, Department of

Anaesthesiology and Intensive Care,

90185 Umeå, Sweden

e-mail: silvana.naredi@anestesi.umu.se

Tel.: +46-90-7850000

Fax: +46-90-136235

G. Lambert · P. Friberg

Sahlgrenska University Hospital,

Department of Clinical Physiology,

Göteborg, Sweden

G. Lambert

Baker Heart Research Institute,

Melbourne, Australia

S. Zäll · E. Edén · M. Tylman ·

A. Bengtsson

Sahlgrenska University Hospital,

Department of Anaesthesiology and

Intensive Care,

Göteborg, Sweden

B. Rydenhag

Sahlgrenska University Hospital,

Department of Neurosurgery,

Göteborg, Sweden
Abstract Objective: The aim of this study was to evaluate the correlation between sympathetic nervous activation and the immune response in patients following subarachnoid haemorrhage (SAH). Design and setting: Clinical study in a neurosurgical intensive care unit. Patients and participants: Fourteen patients with acute non-traumatic SAH were included. Fifteen healthy, agematched volunteers served as controls for measurement of catecholamine spillover. Intervention: Blood sampling for C3a, C5b-9, IL-6, IL-8 and norepinephrine kinetic determination was made within $48 \mathrm{~h}$, at $72 \mathrm{~h}$ and on the 7th-10th day after the SAH. Measurements and results: SAH patients exhibited a profound increase in the rate of norepinephrine spillover to plasma at $48 \mathrm{~h}, 72 \mathrm{~h}$ and 7-10 days after the insult, 3-4 times that in healthy individuals. The plasma levels of C3a, IL-6 and C5b-9 were significantly elevated at $48 \mathrm{~h}$, at $72 \mathrm{~h}$ and 7-10 days after the SAH, but the plasma level of IL- 6 decreased significantly 7-10 days after the SAH. There was no relationship between the magnitude of sympathetic activation and the levels of inflammatory markers. Conclusions: Following SAH a pronounced activation of the sympathetic nervous system and the inflammatory system occurs. The lack of significant association between the rate of spillover of norepinephrine to plasma and the plasma levels of inflammatory markers indicates that the two processes, sympathetic activation and the immune response, following SAH are not quantitatively linked. In spite of a persistent high level of sympathetic activation the plasma level of IL-6 decreased significantly one week after SAH.

Keywords Sympathetic nervous system · Norepinephrine $\cdot$ Cytokines . Complement

\section{Introduction}

There exists evidence that the nervous and the immune systems interact bidirectionally [1, 2, 3, 4]. Research over the past 20 years suggests that norepinephrine (NE) fulfils the criteria for neurotransmittor/neuromodulator in lymphoid organs $[5,6]$. There are conflicting data whether NE, the principal neurotransmitter of the sympathetic nervous system, has immunostimulatory or immunosuppressive effects $[1,7,8,9,10,11]$. Injury to the central nervous system has been linked to immunosuppression [12]. The contradicting results could be due to the fact that there is a difference between the effect of acute stress and chronic stress. In an acute stress situation, immunoenhancement rather than immunosuppression would be of value. On the contrary, chronic stress seems to result in immunosuppression $[12,13,14,15]$. 
After non-traumatic SAH, systemic manifestations such as neurogenic pulmonary oedema and myocardial infarctions are often seen. These systemic complications have been attributed to elevated levels of circulating catecholamines $[16,17,18]$. We have reported a markedly increased rate of spillover of NE to plasma in patients following SAH [19]. This pronounced sympathoexcitation may be due to alterations in brain neuronal activity in response to local ischemia or hypoxia [20, 21, 22]. Patients suffering from $\mathrm{SAH}$ also have symptoms that are correlated with an activated inflammatory response, such as fever, leucocytosis and elevated levels of acutephase proteins [23]. Pro-inflammatory cytokines and complement split products have been detected peripherally and in cerebrospinal fluid in patients with acute stroke and SAH [24, 25, 26, 27]. Whether, and to what extent, sympathetic activation drives, or influences, the immune response following SAH remains unknown.

In order to examine the possible link between sympathetic activation and the inflammatory response, in this study we aimed to evaluate, in a time-course design, the association between the rate of spillover of norepinephrine to plasma and markers of inflammation in patients following SAH.

\section{Materials and methods}

The ethical and isotope committees at Sahlgrenska University Hospital approved the study protocol, and all patients (or their next of kin) gave their informed consent to participate in the study.

\section{Patients}

Fourteen patients (nine females and five males) with acute non-traumatic SAH were included in the study. SAH was diagnosed by computerized tomography (CT). The amount of blood in the subarachnoid space was determined according to the Fisher criteria, scored from 1 (no blood) to 4 (cerebral and/or ventricular blood) [28]. The Hunt and Hess classification was used to assess the clinical neurological condition of the patients at admission: scores range from 1 (asymptomatic or minimal symptoms) to 5 (deep coma) [29].

\section{Monitoring}

The patients had standard ICU monitoring with ECG and invasive systemic blood pressure displayed continuously. Fever was checked regularly at least 4 times/day.
Experimental protocol and blood sampling

Blood was sampled for C3a, SC5-b, IL-6, IL-8 and NE kinetic determination within $48 \mathrm{~h}$ after admission, at $72 \mathrm{~h}$ post-admission and on the 7th to 10th day after the SAH. Radiotracer kinetic determination was used to detect the release of NE from sympathetic nerves since the plasma levels are also influenced by removal (re-uptake, clearance) from plasma [30,31]. Determination of NE spillover in healthy volunteers was made on one occasion only.

\section{Catecholamine kinetic determination}

A tracer dose of L-2, 5,6- $\left[{ }^{3} \mathrm{H}\right] \mathrm{NE}(40-60 \mathrm{Ci} / \mathrm{mmol})$ from New England Nuclear, Boston, MA, USA was delivered at $1.0-1.5 \mu \mathrm{Ci} / \mathrm{min}$ via a peripheral vein. Baseline arterial blood samples were taken at least 30 min after starting the tritium-labelled catecholamine infusion. Blood samples $(10 \mathrm{ml})$ were collected into ice-chilled tubes containing EGTA and glutathione. Plasma was separated by centrifugation and stored at $-80^{\circ} \mathrm{C}$ until assayed. Catecholamines were extracted from plasma $(1 \mathrm{ml})$ and samples of infusate $(10 \mu \mathrm{l})$ using alumina adsorption, separated and quantified by high-performance liquid chromatography with coulometric detection. Timed collection of $\left[{ }^{3} \mathrm{H}\right]$ eluate leaving the electrochemical cell permitted separation of the $\left[{ }^{3} \mathrm{H}\right]$ labelled $\mathrm{NE}$ for subsequent counting by liquid scintillation spectroscopy. Inter-assay coefficients of variation were $4.6 \%$ for endogenous $\mathrm{NE}$ and $3.2 \%$ for $\left[{ }^{3} \mathrm{H}\right] \mathrm{NE}$. Intra-assay coefficients of variation were $2 \%$ and $10 \%$ for endogenous NE and $3 \%$ for both $\left[{ }^{3} \mathrm{H}\right] \mathrm{NE}$.

\section{Calculations}

Total-body catecholamine NE spillover $\left(\mathrm{S}_{\mathrm{TB}}\right)$ was ascertained using the isotope dilution method proposed by Esler et al. [30, 31].

\section{Complement and cytokine determinations}

The concentrations of complement factors $\mathrm{C} 3 \mathrm{a}$ and SC5b-9 and the cytokines IL-6 and IL- 8 were measured. These markers were chosen as pro-inflammatory markers. Blood samples were collected in test tubes containing EDTA $(0.054 \mathrm{ml}$ of $0.34 \mathrm{M}$ EDTA $/ 4.5 \mathrm{ml}$ blood) and immediately stored on ice. The plasma was separated by centrifugation at $4000 \mathrm{rpm}$ for $10 \mathrm{~min}$ at room temperature and samples were frozen within $30 \mathrm{~min}$ in separate test tubes and stored at $-80^{\circ} \mathrm{C}$ until the assays for cytokines and complement factors were 
performed. The levels of plasma immunoreactive $\mathrm{C} 3 \mathrm{a}$, C5b-9, IL-6 and IL-8 were determined by double antibody enzyme-linked immunosorbent assay (ELISA) according to the manufacturer's procedure: C3a (ELISA, Progen Biotechnik, Heidelberg, Germany), SC5b-9 (EIA, Quidel, San Diego, Ca, USA) IL-6 and IL-8 (Elisa R\&D Systems, Minneapolis, USA).

Plasma levels of C3a, C5b-9, IL-6 and IL-8 in patients were compared with the upper limit in validated standardized reference values. The upper limit was used for comparison because plasma levels below this limit can be found in healthy individuals and do not indicate pathology.

\section{Laboratory determinations}

C-reactive protein (CRP) was determined using standard hospital tests. The CRP values represent morning values from the days when the NE calculations and cytokines measurements were performed.

\section{Statistics}

All results are expressed as median and range. MannWhitney non-parametric test was used for comparison of NE spillover between healthy subjects and patients. For determination of elevation from a reference value, Fisher's exact test was used, with the assumption that $5 \%$ of normal values are above the upper limit and 95\% are below the upper limit of the reference value. For comparison between levels of inflammatory markers at different time-points the Kruskal-Wallis test was used. Spearman correlation was used for measurements of correlation between NE spillover and IL-6, C3a, IL-8 and C5b-9 and between CRP and IL-6, C3a, IL-8 and C5b-9. Prism version 4.0 (GraphPad Software, San Diego, CA, USA) was used for statistical analyses.

\section{Results}

The median age of the patients was 51 years (range 40-66 years). In all 14 patients an aneurysm was the cause of the SAH. Fifteen healthy, age-matched volunteers (median age 52 years, range 38-64 years), with no history of neurological or cardiovascular disease and with blood chemistry values within normal ranges served as a control group for measurement of NE spillover.

Three patients were treated with surgical clipping of the aneurysm and in 11 patients the aneurysm was occluded by embolization with platinum coils. All patients were treated within $24 \mathrm{~h}$ after SAH.

All patients received the calcium-blocker nimodipine (Nimotop ${ }^{\circledR}$, Bayer) in order to prevent injury from cere- bral vasospasm. Ten patients received antibiotics as prophylaxis for surgery and intraventricular catheters.

The median Hunt/Hess score was 3.5 (range 1-5), which implies that a majority of the patients presented with significant neurological deterioration. The median Fisher score for the amount of blood in the subarachnoid space was 3.5 (range 1-4), which means that a majority of the patients had a severe SAH.

The median maximal fever at $48 \mathrm{~h}$ was $38.0^{\circ} \mathrm{C}$ (37.4-38.2), at $72 \mathrm{~h}, 38.0^{\circ} \mathrm{C}(37.3-39.3)$ and at $7-10$ days after the SAH, $38.5^{\circ} \mathrm{C}(37.3-39.0 \mathrm{At} 48 \mathrm{~h}$, at $72 \mathrm{~h}$ and at 7-10 days after the SAH, patients had a total body NE spillover that was consistently elevated compared with healthy individuals (Table 1).

The plasma level of C3a was significantly elevated at $48 \mathrm{~h}, 262.6(77-1700) \mathrm{ng} / \mathrm{ml}(n=14 ; p=0.0003)$; at $72 \mathrm{~h}, 339.2(79.1-1791.9) \mathrm{ng} / \mathrm{ml} \quad(n=14 ; p<0.0001)$; and at 7-10 days after the SAH, $380.7(129-4753) \mathrm{ng} / \mathrm{ml}$ $(n=10 ; p<0.0001)$, compared with a reference value of $<200 \mathrm{ng} / \mathrm{ml}$ (Fig. 1a). There was no statistically significant difference in plasma levels of $\mathrm{C} 3 \mathrm{a}$ at $48 \mathrm{~h}, 72 \mathrm{~h}$ or 7-10 days after the SAH $(p>0.05)$ (Fig. 1a).

The plasma level of IL- 6 was significantly increased at $48 \mathrm{~h}, 27.5(2.5-133.2) \mathrm{pg} / \mathrm{ml} \quad(n=14), p<0.0001)$; at $72 \mathrm{~h}, 27.6(6.9-90.6) \mathrm{pg} / \mathrm{ml} \quad(n=14 ; p<0.0001)$; and at 7-10 days after the SAH, $11.4(5.0-34.3) \mathrm{pg} / \mathrm{ml}$ $(n=10 ; p=0.009)$ compared with a reference value of $<12.5 \mathrm{ng} / \mathrm{ml}$ (Fig. 1b). The plasma level of IL-6 was significantly decreased at 7-10 days after the SAH compared with the levels at $48 \mathrm{~h}(p<0.05)$ and $72 \mathrm{~h}(p<0.05$; Fig. 1b).

The plasma level of C5b-9 was significantly elevated at $48 \mathrm{~h}, 203.9(16.1-383.2) \mathrm{ng} / \mathrm{ml}(n=14 ; p=0.0012)$; at $72 \mathrm{~h}, 239.7(6.8-538.9) \mathrm{ng} / \mathrm{ml}(n=14 ; p=0.0012)$; and at 7-10 days after the SAH, $247.7(89.6-538.9) \mathrm{ng} / \mathrm{ml}$ $(n=10 ; p=0.0021)$ compared with a reference value of $<200 \mathrm{ng} / \mathrm{ml}$ (Fig. 1c). There was no statistically significant difference in plasma levels of C5b-9 at $48 \mathrm{~h}$, at $72 \mathrm{~h}$ or at 7-10 days after the SAH $(p>0.05)$ (Fig. 1c).

The plasma level of IL-8 was not significantly elevated at $48 \mathrm{~h}, 4.1(0.9-26.9) \mathrm{pg} / \mathrm{ml}(n=14 ; p>0.05)$; at $72 \mathrm{~h}$, $3.6(1.5-28.4) \mathrm{pg} / \mathrm{ml}(n=14 ; p>0.05)$; or at $7-10$ days after the SAH, $7.3(2.5-13.7) \mathrm{pg} / \mathrm{ml}(n=10 ; p>0.05) \mathrm{com}-$ pared with a reference value of $<30 \mathrm{pg} / \mathrm{ml}$ (Fig. 1d).

Throughout the experimental period there occurred no significant association between the degree of sympathetic

Table 1 Total-body norepinephrine (NE) spillover rate (median values and range) in healthy subjects and in patients with SAH

\begin{tabular}{lcll}
\hline Group & $\begin{array}{l}\text { NE spillover, } \\
\text { nmol/min }\end{array}$ & $\begin{array}{l}\text { Number of } \\
\text { patients }\end{array}$ & $\begin{array}{l}p \\
\text { value }\end{array}$ \\
\hline Healthy & $3.3(1.0-5.2)$ & 15 & \\
Patients 48 $\mathrm{h}$ & $10.5(1.6-23.5)$ & 14 & $p<0.0002$ \\
Patients 72 $\mathrm{h}$ & $9.0(3.5-17.8)$ & 14 & $p<0.0001$ \\
Patients 7-10 days & $12.4(2.2-15.2)$ & 11 & $p<0.0004$ \\
\hline
\end{tabular}


Fig. 1 Plasma levels of pro-inflammatory cytokines: C3a (a), IL-6 (b), C5b-9 (c) and IL-8 (d). Measurements were performed at three occasions in patients: at $48 \mathrm{~h}(n=14)$, at $72 \mathrm{~h}$ $(n=14)$ and at $7-10$ days $(n=10)$ after the initial SAH. The middle line is the median and the box extends from the 25 th to the 75 th percentile. The whiskers extend from the lowest to the highest value. $* p<0.05$. The dotted line corresponds to the upper limit in validated standardized reference values. $\mathrm{C} 3 \mathrm{a}<200 \mathrm{ng} / \mathrm{ml}$, IL- $6<12.5 \mathrm{pg} / \mathrm{ml}$, C $5 \mathrm{~b}-9<200 \mathrm{ng} / \mathrm{ml}$ and IL- $8<30 \mathrm{pg} / \mathrm{ml}$
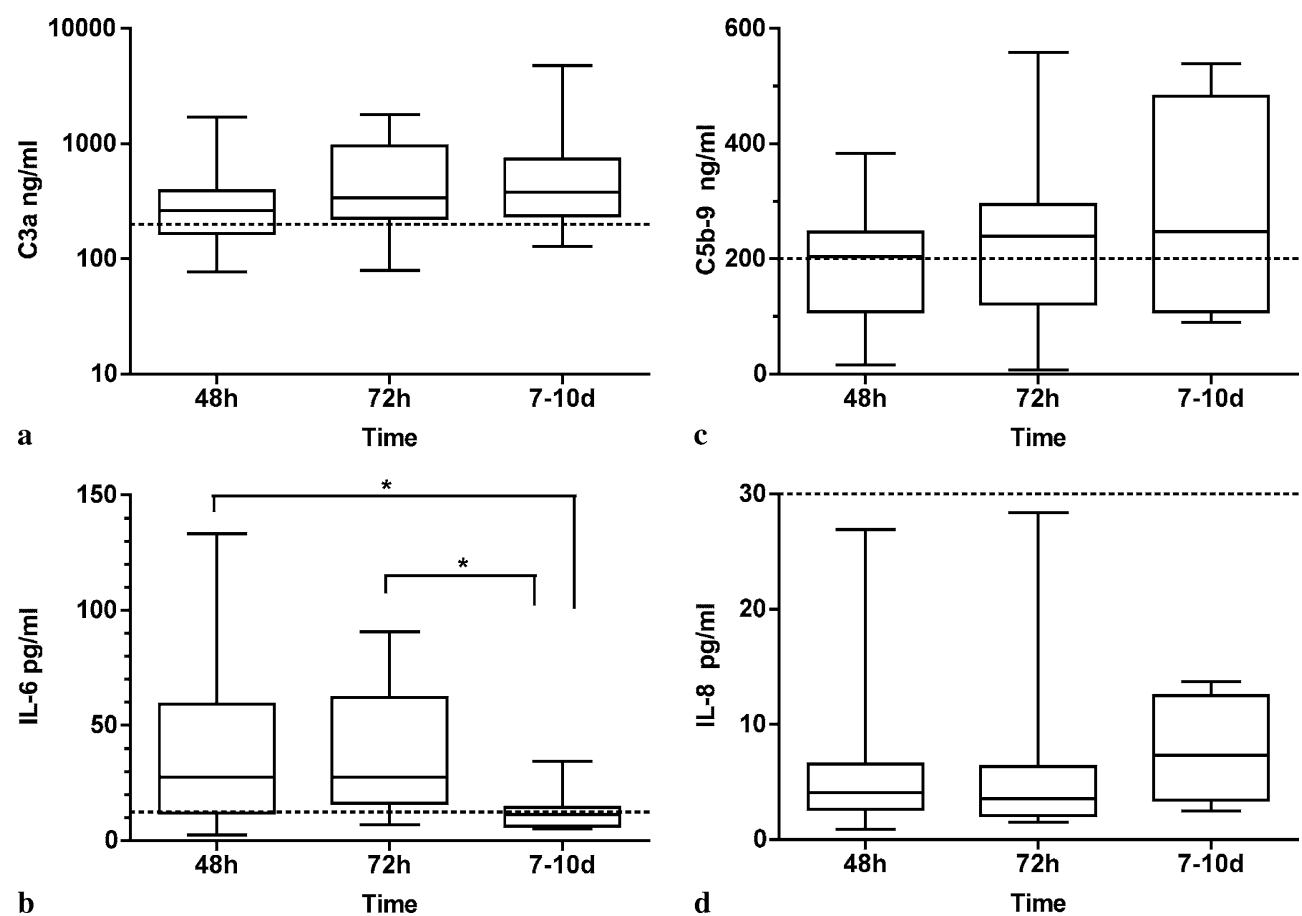

nervous activation and any of the pro-inflammatory markers measured.

At $48 \mathrm{~h}$ after the $\mathrm{SAH}$ the correlation between NE spillover and IL-6 was $(r=0.16, p=0.59)$, C3a $(r=0.34$, $p=0.24)$, IL-8 $(r=0.28, p=0.33)$ and C5b-9 $(r=0.28$, $p=0.34)$. At $72 \mathrm{~h}$ after the SAH the correlation between NA spillover and IL-6 was $(r=0.28, p=0.34)$, C3a $(r=0.14, p=0.63)$, IL-8 $(r=0.34, p=0.23)$ and C5b-9 $(r=0.27, p=0.35)$. Seven to ten days after the SAH the correlation between NA spillover and IL- 6 was $(r=0.22$, $p=0.54), \mathrm{C} 3 \mathrm{a}(r=0.08, p=0.83), \mathrm{IL}-8(r=0.27, p=0.45)$ and C5b-9 $(r=0.28, p=0.43)$.
Median CRP was $11(5-180) \mathrm{mg} / \mathrm{ml}$ at $48 \mathrm{~h}, 64$ $(8-220) \mathrm{mg} / \mathrm{ml}$ at $72 \mathrm{~h}$ and $22(8-60) \mathrm{mg} / \mathrm{ml} 7-10$ days after SAH. There was a statistically significant correlation between CRP and IL- 6 at $72 \mathrm{~h}$ after the SAH $(r=0.59$, $p<0.05)$. There was no statistically significant correlation between CRP and IL-6 at $48 \mathrm{~h}$ and 7-10 days after the SAH. There was no statistically significant correlation between CRP and C3a, C5b-9 or IL-8 at any time-point after the SAH.

No patients received NE or EPI for pressure support. Three patients received dopamine on the days the measurements were performed, in doses from $0.8 \mathrm{mg} / \mathrm{kg}$
Table 2 Total-body norepinephrine (NE) spillover rate and the administration of vasopressor drugs

\begin{tabular}{|c|c|c|c|c|}
\hline Patient & $\begin{array}{l}\text { NE spillover, } \\
\mathrm{nmol} / \mathrm{min} \\
48 \mathrm{~h}\end{array}$ & Vasopressor support & $\begin{array}{l}\text { NE spillover, } \\
\mathrm{nmol} / \mathrm{min} \\
72 \mathrm{~h}\end{array}$ & Vasopressor support \\
\hline 1 & 13.8 & & 11.8 & \\
\hline 2 & 7.9 & & 6.3 & \\
\hline 3 & 13.8 & & 17.8 & \\
\hline 4 & 9.6 & & 12.9 & \\
\hline 5 & 20.8 & & 8.8 & \\
\hline 6 & 1.6 & DA $0.8 \mathrm{mg} / \mathrm{kg}$ & 9.1 & \\
\hline 7 & 11.4 & DA $5 \mathrm{mg} / \mathrm{kg}$ & 13.6 & DA $5 \mathrm{mg} / \mathrm{kg}$ \\
\hline 8 & 6.9 & DA $2 \mathrm{mg} / \mathrm{kg}$ & 6.8 & DA $2 \mathrm{mg} / \mathrm{kg}$ \\
\hline 9 & 23.5 & & 12.6 & \\
\hline 10 & 3.8 & & 4.9 & \\
\hline 11 & 6.6 & & 8.5 & \\
\hline 12 & 14.1 & & 11.8 & \\
\hline 13 & 12.3 & & 8.0 & \\
\hline 14 & 7.1 & & 3.5 & \\
\hline
\end{tabular}

Three patients received dopamine (DA) at the measurement $48 \mathrm{~h}$ after the $\mathrm{SAH}$ and two patients received $\mathrm{DA}$ at the measurement $72 \mathrm{~h}$ after the SAH. 
to $5 \mathrm{mg} / \mathrm{kg}$. No patient received dopamine at the measurement 7-10 days after the SAH (Table 2).

\section{Discussion}

Emerging evidence indicates that the sympathetic nervous system, through its innervation of lymphoid organs, can modulate the inflammatory response $[1,2,3,4,5,6,7]$.

In this study we investigated the release of NE from sympathetic nerves, measured with a radiotracer technique, and simultaneously measured pro-inflammatory markers in patients following $\mathrm{SAH}$, a condition characterized by both sympathetic activation $[16,17,18,19]$ and elevated circulating levels of inflammatory markers $[23,24,25,26,27]$. While a number of studies indicate that catecholamines participate in cytokine production $[1,2,3,4,5,6,7,8,9,10,11,12]$, we found no evidence of a quantitative link between the degree of sympathetic nervous activation and the magnitude of the inflammatory response during a period of 10 days after SAH.

Catecholamines enter plasma principally by overflow of released neurotransmitter to the circulation. Almost all $\mathrm{NE}$ in plasma is derived from sympathetic nerves, but the plasma concentration of NE represents the result of two concurrent processes, spillover of NE into plasma after release from sympathetic nerves and subsequent removal (clearance) of NE from the circulation. Both removal and release processes must be considered if one is to adequately assess the release of NE into plasma, because changes in the former may alter plasma concentrations of NE, irrespectively of any change in NE release from sympathetic nerves [30, 31, 32]. We believe that previous investigations in SAH patients using only endogenous measurements of NE did not give a full picture of NE handling. Thus infusion of tritiated NE, as in the present study, provides more complete knowledge of sympathetic neuronal activity.

Mast cells resemble nerve cells in many respects, and there is ample evidence to indicate that stress can activate mast cells to degranulate. Indeed, this is the presumed basis of psychogenic urticaria [7]. There are conflicting data as to whether NE enhances or suppresses the immune response. In this context the duration of stress exposure may account for the disparate results $[1,7,8,9,10,11,12,13,14]$. Acute stress is an evolutionary adaptation for survival. In a situation of an acute threat to the organism, stress hormones and transmitters are released. Under such conditions immunoenhancement, rather than immunosuppression, would be of value [14]. Chronic stress, on the contrary, could put individuals at greater risk for illness by immunosuppression [12, 14, 33].

We earlier reported that SAH patients have a documented high spillover of NE to the peripheral circulation [19]. Systemic inflammatory response syndrome
(SIRS) is also well documented after SAH, and the incidence has been reported to be as high as $30 \%$.

Patients with SAH have inflammatory symptoms such as fever and increased CRP, which was present also in our patients [23]. In this study we examined the pro-inflammatory markers Il-6, IL-8, C3a and C5b-9. There was a significant increase in plasma levels of IL-6, $\mathrm{C} 3 \mathrm{a}$ and $\mathrm{C} 5 \mathrm{~b}-9$ throughout the experimental period. There was, however, no significant increase in plasma levels of IL-8 at any time point after SAH. The receptors for IL-6 have a lower total capacity than the receptors for IL-8 which could be an explanation why IL-6 but not IL-8 increased.

No patients received NE and only three patients received dopamine on the days the measurements were performed. There is no indication that therapeutically administered vasopressor drugs influenced the NE spillover, as shown in Table 2. The IL-6 levels significantly decreased 1 week after the SAH, even though the sympathetic activation was still prominent.

In an experimental study of pulmonary oedema in NE-stimulated rats, NE stimulation increased the IL-6 concentration to 6 times of the control value after $8 \mathrm{~h}$, but after $16 \mathrm{~h}$ of stimulation the level of IL- 6 had decreased to almost zero, and it did not rise again by $48 \mathrm{~h}$ [34]. Consistent with the present report, in a clinical study of pro-inflammatory cytokines in serum of patients with acute cerebral ischaemia, significantly increased levels of IL- 6 was detected after a few h, the levels of IL- 6 stayed elevated until day 3 and then returned to baseline by day 7 [35].

The levels of C3a and C5b-9, markers of activation of the complement system, were significantly increased throughout the study period. C5b-9 signifies that the complement process has been completed. Increased levels of C3a have been found in plasma and cerebrospinal fluid after SAH [24, 25, 26, 27]. Brain cells can produce complement proteins [36]. One may speculate that the persistent high levels of the complement markers $\mathrm{C} 3 \mathrm{a}$ and C5b-9 could emerge from two processes: peripheral inflammatory activation and production within the central nervous system.

In this study we investigated the possible association between the sympathetic nervous system and the inflammatory response over time in patients following non-traumatic SAH. Sympathetic activation and elevated levels of complement markers and pro-inflammatory cytokines were both evident following SAH. There was no quantitative correlation between the degree of totalbody NE spillover, as measured with the state-of-the-art technique reflecting general sympathetic activity, and the magnitude of the inflammatory response. An interesting observation was that the initially increased level of IL-6 was significantly decreased 1 week after the SAH, in spite of a persistent high level of sympathetic activation. Even though there were a limited number of patients in 
this study, to our knowledge it is the first clinical study in which the sympathetic activation was measured with a radiotracer technique simultaneously with markers of inflammation over a longer period of time. The clinical results of this study could support the hypothesis that sympathetic activation can both stimulate and suppress inflammation if followed over a longer period of time.

In conclusion, elevated levels of pro-inflammatory markers and increased levels of NE were both evident up to 1 week following SAH. In spite of a persistent high level of sympathetic activation, IL-6 was significantly decreased 1 week after SAH. Suffice to say, the interaction between the sympathetic nervous system and immunomodulatory mechanisms in SAH is complex and needs further study.

Acknowledgements. This study was performed at Sahlgrenska University Hospital, Göteborg, Sweden. The study was supported by grants from the Regional Health Care Authority of West Sweden, The Göteborg Medical Society, the Swedish Society of Medicine, the Swedish Medical Research Council and the National Health and Medical Council of Australia.

\section{References}

1. Moynihan J, Kruszewska B, Madden K, Callahan T (2004) Sympathetic nervous system regulation of immunity. J Neuroimmunol 147:87-90

2. Elenkov I, Wilder R, Chrousos G, Vizi S (2000) The sympathetic nerve an integrative interface between two super systems: the brain and the immune system. Pharmacol Rev 52:595-638

3. Maier S, Watkins L (1998) Cytokines for psychologists: implications of bidirectional immune-to-brain communication for understanding behaviour, mood and cognition. Psychol Rev 105:83-107

4. Watkins L, Maier S (2005) Immune regulation of central nervous system functions. From sickness responses to pathological pain. J Intern Med 257:139-155

5. Felten D, Felten S, Bellinger D, Carlsson S, Ackerman K, Madden K, Olschowki J, Livnat S (1987) Noradrenergic sympathetic neural interactions with the immune system: structure and function. Immunol Rev 100:225-260

6. Felten D, Felten S, Bellinger D, Madden K (1993) Fundamental aspects of neural-immune signaling. Psychother Psychosom 60:46-56

7. Black P (2002) Stress and the inflammatory response: a review of neurogenic inflammation. Brain Behav Immun 16:622-653

8. Connor T, Brewer C, Kelley J, Harkin A (2005) Acute stress response suppresses pro-inflammatory cytokines TNF-alfa and IL-1beta independent of a catecholamine-driven increase in IL-10 production. J Neuroimmunol 159:119-128

9. Volk T, Döpfmer U, Schmutzler M, Rimpau S, Schnitzler H, Konertz W, Hoeflich C, Döcke W, Spies C, Volk H, Kox W (2003) Stress induced IL-10 does not seem to be essential for early monocyte deactivation following cardiac surgery. Cytokine 24:237-243
10. van der Poll T, Jansen J, Endert E, Sauerwein $\mathrm{H}$, van Deventer $\mathrm{S}$ (1994) Noradrenaline inhibits lipopolysaccharide-induced tumour necrosis factor and interleukin 6 production in human whole blood. Infect Immun 62:2046-2050

11. Bürger A, Benicke M, Deten A, Zimmer HG (2001) Catecholamines stimulate interleukin-6 synthesis in rat cardiac fibroblasts. AJP Heart 281:14-21

12. Meisel C, Schwab JM, Prass K, Meisel A, Dirnag U (2005) Central nervous system injury induced immune deficiency syndrome. Nat Rev/Neuroscience 6:775-786

13. Dhabhar F (2003) Stress, leukocyte trafficking, and the augmentation of skin immune function. Ann N Y Acad Sci 992:205-217

14. Dhabhar F, McEven B (1997) Acute stress enhances while chronic stress suppresses cell-mediated immunity in vivo: a potential role for leucocyte trafficking. Brain Behav Immun 11:286-306

15. Tracey K (2002) The inflammatory reflex. Nature 420:853-859

16. Macmillan C, Grant I, Andrews P (2002) Pulmonary and cardiac sequelae of subarachnoid haemorrhage: time for active management? Intensive Care Med 28:1012-1023

17. Cruickshank JM, Neil-Dwyer G, Stott AW (1974) Possible role of catecholamines, corticosteroids and potassium in production of electrocardiographic abnormalities associated with subarachnoid haemorrhage. Br Heart J 36:697-706

18. Dilraj A, Botha JB, Rambiritch V, Miller R, van Dellen JR (1992) Levels of catecholamines in plasma and cerebrospinal fluid in aneurysmal subarachnoid hemorrhage. Neurosurg $31: 42-51$
19. Naredi S, Lambert G, Edén E, Zäll S, Runnerstam M, Rydenhag B, Friberg P (2000) Increased sympathetic nervous activity in patients with non-traumatic subarachnoid hemorrhage. Stroke 31:901-906

20. Dampney R, Moon E (1980) Role of ventrolateral medulla in vasomotor response to cerebral ischemia. Am J Physiol 239:349-358

21. Reis D, Morrison S, Ruggiero D (1988) The $\mathrm{C} 1$ area of the brainstem in tonic and reflex control of blood pressure. Hypertension 11:18-23

22. Sun M, Reis D (1994) Hypoxia selectively excites vasomotor neurons of rostral ventrolateral medulla in rats. Am J Physiol 266:R245-R256

23. Yoshimoto Y, Tanaka Y, Hoya K (2001) Acute systemic inflammatory response syndrome in subarachnoid hemorrhage. Stroke 32:1989-1993

24. Hidetoshi K, Takashi S (1989) Activated complement components $\mathrm{C} 3 \mathrm{a}$ and $\mathrm{C} 4 \mathrm{a}$ in cerebrospinal fluid and plasma following subarachnoid hemorrhage. J Neurosurg 71:741-746

25. Fassbender K, Hodapp B, Rossol S, Bertsch T, Schmeck J, Schutt S, Fritzinger M, Horn P, Vajkoczy P, Kreisel S, Brunner J, Schmiedek P, Hennerici M (2001) Inflammatory cytokines in subarachnoid haemorrhage: association with abnormal blood flow velocities in basal cerebral arteries Neurol Neurosurg Psychiatry 70:534-537

26. Mathiesen T, Andersen B, Loftenius A, von Holst H (1993) Increased interleukin-6 levels in cerebrospinal fluid following subarachnoid hemorrhage. J Neurosurg 78:562-567

27. Kasuya H, Shimizu T (1989) Activated complement components $\mathrm{C} 3 \mathrm{a}$ and $\mathrm{C} 4 \mathrm{a}$ in cerebrospinal fluid and plasma following subarachnoid hemorrhage. J Neurosurg 71:741-746 
28. Fisher CM, Kistler JP, Davis JM (1980) Relation of cerebral vasospasm to subarachnoid hemorrhage visualized by computerized tomographic scanning. Neurosurgery 6:1-9

29. Hunt WE, Hess RM (1968) Surgical risk as related to time of intervention in the repair of intracranial aneurysms. J Neurosurg 28:14-20

30. Eisenhofer G (2005) Sympathetic nerve function. Assessment by radioisotope dilution analysis. Clin Auton Res 15:264-283
31. Esler M, Jackmann G, Bobik A, Kelleher D, Jennings G, Leonard P, Skews H, Korner P (1979) Determination of norepinephrine apparent release and clearance in humans. Life Sci 25:1461-1470

32. Esler M, Jennings G, Leonard P Sacharias N, Burke F, Johns J, Blombery P (1984) Contribution of individual organs to total noradrenaline release in humans. Acta Physiol Scand 527:11-16

33. Padgett D, Glaser R (2003) How stress influences the immune response. Trends Immunol 24:444-448
34. Raßler B, Reißig C, Briest W, Tannapfel A, Zimmer HG (2003) Pulmonary edema and pleural effusion in norepinephrine-stimulated rats hemodynamic or inflammatory effect? Mol Cell Biochem 250:55-63

35. Fassbender K, Rossol S, Kammer T, Daffertshofer M, Wirth S, Dollman M, Hennerici M (1994) Proinflammatory cytokines in serum of patients with acute cerebral ischemia: kinetics of secretion and relation to the extent of brain damage and outcome of disease. J Neurol Sci 122:135-139

36. Van Beek J, Elward K, Gasque P (2003) Activation of complement in the central nervous system. Ann N Y Acad Sci 992:56-71 